\title{
Nutrition in pregnancy: the argument for including a source of choline
}

This article was published in the following Dove Press journal:

International Journal of Women's Health

20 April 2013

Number of times this article has been viewed

\section{Steven H Zeisel}

Nutrition Research Institute at Kannapolis, Department of Nutrition, University of North Carolina at Chapel Hill, Kannapolis, NC, USA

Video abstract

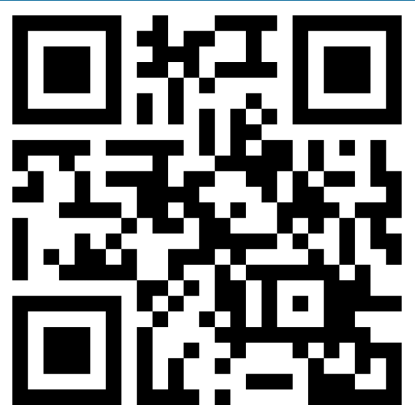

Point your SmartPhone at the code above. If you have a QR code reader the video abstract will appear. Or use: http://dvpr.es/XOXaXO

Correspondence: Steven H Zeisel UNC-Chapel Hill Nutrition Research Institute, UNC Gillings Global School of Public Health and School of Medicine, 500 Laureate Way, Kannapolis, NC 2808I, USA

$\mathrm{Tel}+\mathrm{I} 7042505003$

$\mathrm{Fax}+\mathrm{I} 704250500$

Email steven_zeisel@unc.edu
Abstract: Women, during pregnancy and lactation, should eat foods that contain adequate amounts of choline. A mother delivers large amounts of choline across the placenta to the fetus, and after birth she delivers large amounts of choline in milk to the infant; this greatly increases the demand on the choline stores of the mother. Adequate intake of dietary choline may be important for optimal fetal outcome (birth defects, brain development) and for maternal liver and placental function. Diets in many low income countries and in approximately one-fourth of women in high income countries, like the United States, may be too low in choline content. Prenatal vitamin supplements do not contain an adequate source of choline. For women who do not eat foods containing milk, meat, eggs, or other choline-rich foods, a diet supplement should be considered.

Keywords: pregnancy, choline, birth defects, brain development, liver function, placenta

\section{Introduction}

We present the argument for including a source of choline in the diets of pregnant women. Briefly, this argument is based on several elements (Figure 1):

1. Choline is an essential nutrient that is important for fetal development, as well as for liver and placental function; ${ }^{1}$

2. The mother delivers large amounts of choline across the placenta to the fetus, and after birth delivers large amounts of choline in milk to the infant; ${ }^{2}$

3. Choline is normally eaten in foods like milk, eggs, and meats. ${ }^{3}$ Prenatal vitamin supplements do not contain an adequate source of choline, yet in high income countries almost a quarter of women consume diets low in choline content, and several small studies suggest that in low income countries most women eat low choline foods. $^{4-9}$

\section{The functions of choline}

Choline is used for several critical purposes. It is a precursor for the phospholipid phosphatidylcholine, which is a major constituent of membranes, lipoproteins, bile, and surfactants. ${ }^{2,10}$ Also, it is a precursor for betaine, which is needed for normal kidney glomerular function and perhaps for mitochondrial function. ${ }^{11,12}$ Choline, via betaine, provides one-carbon units to the methionine cycle that are used for methylation reactions. ${ }^{12,13}$ Finally, choline is needed to form acetylcholine, an important neurotransmitter. ${ }^{14}$

Choline metabolism is closely related to the metabolism of several B-vitamins and methionine. The pathways intersect at the methylation of homocysteine to 


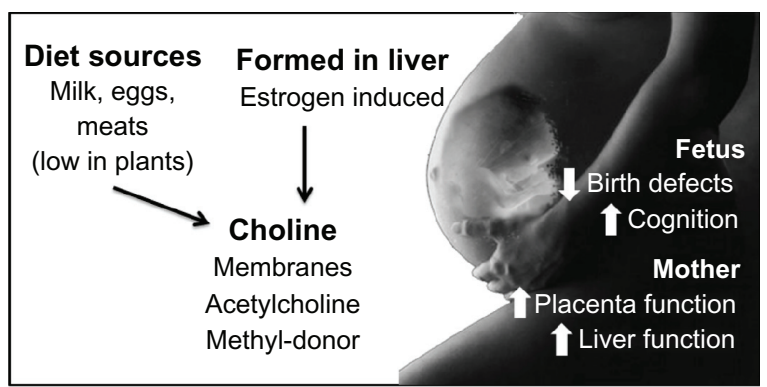

Figure I Women, during pregnancy and lactation, should eat diets that contain adequate amounts of choline.

Notes: Phosphatidylcholine, a source of choline, is formed in the liver, and the gene responsible for endogenous synthesis is induced by estrogen during pregnancy. Choline is also derived from the diet, where milk, meat, and eggs are rich sources. Diets in many low income countries and in approximately a fourth of women in high income countries may be too low in choline content. In addition, there are common genetic polymorphisms that increase the dietary choline requirement for many women. Adequate intake of dietary choline may be important for optimal fetal outcome (birth defects, brain development) and may also be important for maternal liver and placental function.

form methionine. Choline, after being oxidized to betaine, can be the methyl-group donor for this reaction. Alternatively, 5-methyltetrahydrofolate can be the methyl-group donor for methionine formation in a vitamin B12-dependent pathway. Thus, the dietary requirement for choline, folate, and methionine are all interrelated, with some, but not all of the requirements for each of these nutrients possibly being met by more availability of one of the other nutrients in the diet; conversely, the requirement for choline is increased by methionine or folate deficiency. ${ }^{15-17}$

Adults eating diets very low in choline develop fatty liver, liver cell death, and muscle damage. ${ }^{18-22}$ The fatty liver that develops in choline deficiency is related to the synthesis of very low-density lipoprotein, which is needed to package triglycerides that are then secreted from the liver. ${ }^{23}$ Phosphatidylcholine is a required component of the very low-density lipoprotein envelope, and when it is not available, triglycerides accumulate in the liver cytosol. ${ }^{23}$ Liver and muscle cells die when deprived of choline because mitochondria malfunction, leak free radicals, and trigger apoptotic cell death. ${ }^{24-27}$ Abnormalities in liver function tests during pregnancy are relatively common, and may be the result of pregnancy-specific disorders such as preeclampsia or acute fatty liver of pregnancy, ${ }^{28}$ but more commonly they may be caused by nonalcoholic fatty liver disease (NAFLD) ${ }^{28}$ NAFLD is a common disorder, affecting $\sim 30 \%$ of people in the general population and up to $96 \%$ of obese individuals. It encompasses a spectrum ranging from fatty liver to advanced liver injury. ${ }^{30}$ Both pregnancy and NAFLD are associated with insulin resistance, and women with features of metabolic syndrome who develop unexplained abnormalities in liver function in pregnancy and have ultrasound depositions of fat are most likely to have NAFLD. ${ }^{28}$ We recently observed that people with specific clusters of genetic polymorphisms (SNPs) in genes of choline metabolism are more likely to have NAFLD ${ }^{29}$ (we discuss some of these polymorphisms, and the metabolic inefficiencies they cause, later). ${ }^{31}$ Perhaps diets that are low in choline content consumed during pregnancy also predispose pregnant women to develop of NAFLD; no studies have been reported that test this hypothesis.

Dietary choline may also be important for placental function in pregnant women. Higher dietary intake of choline improves signaling mechanisms responsible for placental angiogenesis and may mitigate some of the pathological antecedents of preeclampsia. ${ }^{32}$ The epigenome of the human placenta is especially responsive to maternal choline intake; for example, higher maternal choline intake altered gene methylation and the expression of placental corticotropinreleasing hormone, a key regulator in stress response. ${ }^{33}$ This suggests that poor maternal choline intake may adversely affect maternal and fetal responses to stress.

Choline is especially important for fetal development. In the United States, women eating diets that are lower in choline content $(150 \mathrm{mg} /$ day $)$ are at significantly greater risk for having a baby with a neural tube defect $(4 \times \text { greater risk })^{4}$ or an orofacial cleft $(1.7 \times \text { greater risk })^{34}$ than are women eating diets higher in choline content. In rodent models, maternal intake of choline during pregnancy influenced the development of the hippocampus in the fetus and memory function in the pup. There was more than a twofold difference in rates of hippocampal neurogenesis in the fetal brain between fetuses from dams eating low choline versus high choline diets,,$^{35}$ and for more than 200 days after birth, hippocampal neurogenesis rates remained elevated in pups from highcholine diet mothers compared to controls. ${ }^{36}$ This effect of maternal choline on fetal brain development occurred during a sensitive window in development (embryonic days 11-17; this period in rodent brain development is equivalent to 25 weeks gestation through to 4 years of age in human brain development). Hippocampal function in the pups born from high-choline diet mothers was significantly enhanced when compared to controls, as assessed by maze performance, ${ }^{37}$ and by long-term potentiation (an electrical property of brain that is active in memory processing). ${ }^{38}$ These effects lasted the lifetime of the offspring. ${ }^{39}$ The enhanced neuronal population created during the sensitive window of hippocampal neurogenesis likely set the stage for enhanced memory performance in later life. 
Though there have been studies in adult humans reporting better cognitive function in those that eat diets higher in choline, ${ }^{40}$ there have been no adequately powered studies to determine if choline nutrition during pregnancy enhances memory in infants. A small study ( 140 women in the United States; 70 treated, 70 placebo), designed to test whether supplemental choline (as phosphatidylcholine) could be administered safely to pregnant and lactating women, found that there may be no advantage to supplementing these mothers with phosphatidylcholine (that delivers $750 \mathrm{mg}$ /day) in terms of enhanced brain development in their infants at 1 year of age ${ }^{41}$ These women were eating diets that were already adequate for choline before the supplementation; perhaps supplementation should be considered in women eating diets low in choline. This study was not powered to determine whether women with genetic polymorphisms (see discussion below) need more choline during pregnancy to assure optimal infant brain development.

Another reason that pregnant women may benefit from diets adequate in choline content may be that choline protects fetuses from certain environmental insults. Exposure of the fetus to alcohol can cause abnormalities in behavior and organ structures that range from barely detectable, to birth defects, to fetal loss. ${ }^{42}$ When pregnant rat dams were exposed to alcohol during pregnancy, their offspring had reduced birth weight and brain weight, delays in eye opening and incisor emergence, and alterations in the development of the righting reflex, geotactic reflex, cliff avoidance, reflex suspension, and hind limb coordination. However if the pregnant rats were also treated with choline, some of the effects (on birth and brain weight, incisor emergence, and most behavioral measures) from alcohol were attenuated in their pups. In fact, the behavioral performance of ethanolexposed pups treated with choline did not differ from that of controls. ${ }^{43-45}$ This effect from choline occurred without changing alcohol exposure, as blood alcohol levels were not changed by choline. ${ }^{44}$ Several small clinical trials are underway in humans to determine if choline supplementation during pregnancy can mitigate the effects of alcohol exposure in humans.

Based on the role of choline in liver and placental function, on choline's effect on the risk for birth defects, and perhaps on the potential effects on hippocampal development and protection from some of the negative effects of alcohol, there is a strong functional argument that choline is an important nutrient during pregnancy. Must this choline come from the diet, and do women normally consume diets high in choline?

\section{The sources of choline}

As we develop the argument for including a source of choline in the diets of pregnant women, it will be important to understand what the sources for choline are. People have the capacity to synthesize phosphatidylcholine by methylating phosphatidylethanolamine, using S-adenosylmethionine as the methyl donor. ${ }^{46}$ This pathway is primarily present in the liver, and is the only metabolic pathway for forming new choline molecules, diet being the only other source. Foods like milk, eggs, and meat are good sources of choline, while most plants are poorer sources of choline (a relatively comprehensive list of the foods that contain choline is available from the United States Department of Agriculture ${ }^{47}$ Most of the choline in foods is present in the form of phosphatidylcholine, a constituent of membranes. Choline intake in the diet has been estimated to vary by as much as threefold; the lowest quartile and the highest quartile of intake were approximately $150 \mathrm{mg}$ and $500 \mathrm{mg} /$ day choline equivalents, respectively, in the Framingham Offspring Study, ${ }^{5}$ the Atherosclerosis Risk In Communities study, ${ }^{6,7}$ and the Nurse's Health Study. ${ }^{8}$ Intake of choline is likely lower in low income countries. ${ }^{9}$ The United States recommended that the adequate intake for choline in pregnant women is $450 \mathrm{mg} / \mathrm{day}^{1}{ }^{1}$

Until the 1990s, there was an argument among nutrition scientists as to whether humans could meet their requirement for choline solely through endogenous biosynthesis. It was only when the hypothesis was tested in experiments where people were fed low choline diets and then developed liver and muscle damage that the argument was settled for men and postmenopausal women; ${ }^{20}$ however, many premenopausal women did not get sick when fed low choline diets for 7 weeks. ${ }^{20}$ This was explained when it was discovered that expression of the gene (PEMT) for the protein catalyzing the endogenous synthesis of phosphatidylcholine in the liver was induced by estrogen.$^{48}$ Maximal induction of PEMT expression occurs only at the high estrogen concentrations achieved during pregnancy. ${ }^{48}$ It appears that young women are designed to have the extra capacity to make choline, thereby making them less dependent on diet as a source of choline. Nonetheless, it is important to recognize that choline itself is a source of the methyl-groups consumed during the production of phosphatidylcholine by the PEMT pathway (choline $\rightarrow$ betaine $\rightarrow$ S-adenosylmethionine $\rightarrow$ phosphatidylcholine),$^{49}$ and that female versus male mice oxidize more choline to support endogenous biosynthesis via the PEMT pathway. ${ }^{50}$ Thus, de novo production of 
phosphatidylcholine via the PEMT is not entirely independent of preformed choline.

The extra capacity for producing choline in the liver is probably needed because pregnancy places large demands on maternal choline reserves. Choline is actively transported across the placenta and achieves much higher choline concentrations in fetal tissues than in maternal blood (about 14-fold). ${ }^{51-54}$ In pregnant rats, this excessive demand for choline exceeds the increased capacity to make choline in the liver, and results in a depletion of maternal choline stores. ${ }^{55}$ After the infant is born, lactation further increases the demands on maternal stores of choline, as this nutrient is secreted into milk at high concentrations. ${ }^{56-61}$ In lactating rats, this excessive demand for choline for milk production exceeds the increased capacity to make choline in the liver, and results in further depletion of maternal choline stores. ${ }^{55}$ In humans, the depletion of choline-derived methyl donors (ie, betaine, dimethylglycine, and sarcosine) is observed even with intakes that approximate the current adequate intake of choline in pregnant women. ${ }^{62}$ Thus, though pregnant women benefit from an estrogen-induced enhancement of the endogenous production of choline, they likely still depend on dietary sources of choline to meet their choline demands through pregnancy and lactation.

The production of phosphatidylcholine via PEMT activity is also an important pathway for the incorporation of docosahexaenoic acid (DHA) into phosphatidylcholine. ${ }^{63}$ This may increase the delivery of DHA to the fetus where it is important for fetal brain development. ${ }^{64}$

Variation in choline metabolizing genes may further modify the requirement for choline during pregnancy. In the studies discussed earlier on human choline requirements, $56 \%$ of young women with estrogen did not become sick when eating a low choline diet, but $44 \%$ did develop fatty liver and liver damage. ${ }^{20}$ The latter group of young women had metabolic inefficiencies in choline metabolism caused by common SNPs in genes of choline and folate metabolism. ${ }^{65-67}$ For example, 22\% of women in the United States have two variant alleles for PEMT (the gene responsible for the endogenous production of choline; rs12325817). ${ }^{19,20,54,66}$ This SNP makes this gene unresponsive to estrogen, ${ }^{68}$ reducing these women to the sad state of men who must eat choline. Sixty percent of women in the United States have a variant allele for SNP in the gene 5,10-methylenetetrahydrofolate dehydrogenase(MTHFD1; G1958A rs2236225) that significantly increased young women's dietary requirement for choline because more choline was needed as a methyl-donor to replace missing methyltetrahydrofolate. ${ }^{67,69}$ Thus, women with these SNPs should make sure that they eat adequate amounts of choline during pregnancy.

\section{Is there a downside to including a source of choline in the diets of pregnant women?}

As with any treatment, there are costs and benefits that must be weighed. Choline is available in many forms: as free choline and as choline-containing molecules such as phosphatidylcholine. In foods, much of the choline is present as phosphatidylcholine. ${ }^{3}$ Choline and phosphatidylcholine are considered to be Generally Recognized as Safe by the United States Food and Drug Administration, and phosphatidylcholine is commonly added to food products (also called lecithin). For example, phosphatidylcholine is added to chocolate to keep the cocoa in suspension; without it, chocolate bars would turn white as the cocoa sinks to the bottom of the bar. Despite this designation as safe, there are potential side effects that should be considered.

Choline in the diet that reaches the large intestine (it is normally absorbed in the small intestine) can be converted by gut microbes to form trimethylamine (TMA) which is then absorbed and oxidized in the liver to form trimethylamine oxide (TMAO). After large oral doses of choline (grams), the TMA formed from choline imparts a fishy body odor to people. ${ }^{1,70}$ Phosphatidylcholine is not a good substrate for the bacterial formation of TMA, and even large doses do not seem to impart a fishy body odor. ${ }^{70,71}$

The formation of TMAO from dietary choline has an addition potential for risk. Elevated plasma concentrations of TMAO were associated with increased risk for cardiovascular disease in a small human study. ${ }^{72}$ In addition, dietary supplementation of apolipoprotein $\mathrm{E}$ knockout mice with choline or TMAO increased the development of atherosclerotic lesions. ${ }^{72}$

Additional side effects observed due to large doses of orally administered choline include vomiting, sweating, gastrointestinal side effects, and hypotension. A tolerable upper limit of choline for adults has been set at $3.5 \mathrm{~g}$ /day in the United States. ${ }^{1}$

A small study assessing the safety of adding $750 \mathrm{mg}$ choline (as phosphatidylcholine) per day for 35 weeks ( 18 weeks of pregnancy through 90 days of lactation) to the diet of pregnant and lactating women reported no adverse events in mothers $(n=140)$ or babies $(n=99)$ due to the supplement. ${ }^{41}$ 
Given the potential adverse effects, it seems prudent to advocate that the intake of choline during pregnancy stay within the range of normal human exposure to choline from the diet (between half a gram and 1 gram per day). If possible, foods containing choline should be added to the diet. When this is not tenable, then phosphatidylcholine may have advantages over choline in a supplement, as fishy odor may be avoided.

\section{The argument for including a source of choline}

Women, during pregnancy and lactation, should eat diets that contain adequate amounts of choline. The mother delivers large amounts of choline across the placenta to the fetus, and after birth delivers large amounts of choline in milk to the infant; this greatly increases the demand on the choline stores of the mother. Adequate intake of dietary choline may be important for optimal fetal outcomes (birth defects, brain development) and for maternal liver and placental function. Diets in many low income countries and in approximately one-fourth of women in high income countries, like the United States, may be too low in choline content. Prenatal vitamin supplements do not contain an adequate source of choline. For women who do not eat diets containing milk, meat, eggs, or other choline-rich foods, a diet supplement should be considered.

\section{Acknowledgments}

Financial support was provided by a grant from the National Institutes of Health (DK05595) and a grant from the Bill and Melinda Gates Foundation.

\section{Disclosure}

The author reports no conflicts of interest in this work. SH Zeisel has no financial interest in relation to this manuscript. Dr Zeisel received grant support from the Pfizer Nutrition, Balchem, and the Egg Nutrition Research Center for studies other than those described in this paper. Dr Zeisel is on the Scientific Advisory Board for Solae, American Pistachio Growers, Dupont, Metabolon, and GenoVive.

\section{References}

1. Institute of Medicine, National Academy of Sciences USA. Choline. In: Dietary Reference Intakes for Folate, Thiamin, Riboflavin, Niacin, Vitamin B12, Pantothenic Acid, Biotin, and Choline. Washington, DC: National Academy Press; 1998:390-422.

2. Zeisel SH. Choline: critical role during fetal development and dietary requirements in adults. Annu Rev Nutr. 2006;26:229-250.

3. Zeisel SH, Mar MH, Howe JC, Holden JM. Concentrations of choline-containing compounds and betaine in common foods. $J$ Nutr. 2003;133(5):1302-1307.
4. Shaw GM, Carmichael SL, Yang W, Selvin S, Schaffer DM. Periconceptional dietary intake of choline and betaine and neural tube defects in offspring. Am J Epidemiol. 2004;160(2):102-109.

5. Cho E, Zeisel SH, Jacques P, et al. Dietary choline and betaine assessed by food-frequency questionnaire in relation to plasma total homocysteine concentration in the Framingham Offspring Study. Am J Clin Nutr. 2006;83(4):905-911.

6. Bidulescu A, Chambless LE, Siega-Riz AM, Zeisel SH, Heiss G. Usual choline and betaine dietary intake and incident coronary heart disease: the Atherosclerosis Risk in Communities (ARIC) study. BMC Cardiovasc Disord. 2007;7:20.

7. Bidulescu A, Chambless LE, Siega-Riz AM, Zeisel SH, Heiss G. Repeatability and measurement error in the assessment of choline and betaine dietary intake: the Atherosclerosis Risk in Communities (ARIC) study. Nutr J. 2009;8:14.

8. Cho E, Willett WC, Colditz GA, et al. Dietary choline and betaine and the risk of distal colorectal adenoma in women. J Natl Cancer Inst. 2007;99(16):1224-1231.

9. Gossell-Williams M, Fletcher H, McFarlane-Anderson N, Jacob A, Patel J, Zeisel S. Dietary intake of choline and plasma choline concentrations in pregnant women in Jamaica. West Indian Med J. 2005;54(6):355-359.

10. Hollenbeck CB. An introduction to the nutrition and metabolism of choline. Cent Nerv Syst Agents Med Chem. 2012;12(2):100-113.

11. Burg M. Molecular basis of osmotic regulation. Am J Physiol. 1995;268(6 Pt 2):F983-F996.

12. Johnson AR, Craciunescu CN, Guo Z, et al. Deletion of murine choline dehydrogenase results in diminished sperm motility. FASEB $J$. 2010;24(8):2752-2761.

13. Teng YW, Mehedint MG, Garrow TA, Zeisel SH. Deletion of betaine-homocysteine S-methyltransferase in mice perturbs choline and 1-carbon metabolism, resulting in fatty liver and hepatocellular carcinomas. J Biol Chem. 2011;286(42):36258-36267.

14. Cohen EL, Wurtman RJ. Brain acetylcholine: control by dietary choline. Science. 1976;191(4227):561-562.

15. Varela-Moreiras G, Selhub J, da Costa K, Zeisel SH. Effect of chronic choline deficiency in rats on liver folate content and distribution. J Nutr Biochem. 1992;3:519-522.

16. Selhub J, Seyoum E, Pomfret EA, Zeisel SH. Effects of choline deficiency and methotrexate treatment upon liver folate content and distribution. Cancer Res. 1991;51(1):16-21.

17. Shin W, Yan J, Abratte CM, Vermeylen F, Caudill MA. Choline intake exceeding current dietary recommendations preserves markers of cellular methylation in a genetic subgroup of folate-compromised men. J Nutr. 2010;140(5):975-980.

18. Zeisel SH, Da Costa KA, Franklin PD, et al. Choline, an essential nutrient for humans. FASEB J. 1991;5(7):2093-2098.

19. Fischer LM, da Costa KA, Kwock L, Galanko J, Zeisel SH. Dietary choline requirements of women: effects of estrogen and genetic variation. Am J Clin Nutr. 2010;92(5):1113-1119.

20. Fischer LM, daCosta K, Kwock L, et al. Sex and menopausal status influence human dietary requirements for the nutrient choline. Am J Clin Nutr. 2007;85(5):1275-1285.

21. da Costa KA, Badea M, Fischer LM, Zeisel SH. Elevated serum creatine phosphokinase in choline-deficient humans: mechanistic studies in C2C12 mouse myoblasts. Am J Clin Nutr. 2004;80(1):163-170.

22. Buchman AL, Ament ME, Sohel M, et al. Choline deficiency causes reversible hepatic abnormalities in patients receiving parenteral nutrition: proof of a human choline requirement: a placebo-controlled trial. JPEN J Parenter Enteral Nutr. 2001;25(5):260-268.

23. Noga AA, Vance DE. A gender-specific role for phosphatidylethanolamine $\mathrm{N}$-methyltransferase-derived phosphatidylcholine in the regulation of plasma high density and very low density lipoproteins in mice. J Biol Chem. 2003;278(24):21851-21859.

24. Albright CD, da Costa KA, Craciunescu CN, Klem E, Mar MH, Zeisel SH. Regulation of choline deficiency apoptosis by epidermal growth factor in CWSV-1 rat hepatocytes. Cell Physiol Biochem. 2005;15(1-4):59-68. 
25. Holmes-McNary MQ, Loy R, Mar MH, Albright CD, Zeisel SH. Apoptosis is induced by choline deficiency in fetal brain and in PC12 cells. Brain Res Dev Brain Res. 1997;101(1-2):9-16.

26. Albright CD, Lui R, Bethea TC, Da Costa KA, Salganik RI, Zeisel SH. Choline deficiency induces apoptosis in SV40-immortalized CWSV-1 rat hepatocytes in culture. FASEB J. 1996;10(4):510-516.

27. Holmes-McNary MQ, Baldwin AS Jr, Zeisel SH. Opposing regulation of choline deficiency-induced apoptosis by $\mathrm{p} 53$ and nuclear factor kappaB. J Biol Chem. 2001;276(44):41197-41204.

28. Page LM, Girling JC. A novel cause for abnormal liver function tests in pregnancy and the puerperium: non-alcoholic fatty liver disease. BJOG. 2011;118(12):1532-1535.

29. Corbin KD, Abdelmalek MF, Spencer MD, et al. Genetic signatures in choline and 1-carbon metabolism are associated with the severity of hepatic steatosis. FASEB J. In press 2013.

30. Ong JP, Younossi ZM. Epidemiology and natural history of NAFLD and NASH. Clin Liver Dis. 2007;11(1):1-16, vii.

31. Corbin KD, Zeisel SH. Choline metabolism provides novel insights into nonalcoholic fatty liver disease and its progression. Curr Opin Gastroenterol. 2012;28(2):159-165.

32. Jiang X, Bar HY, Yan J, et al. A higher maternal choline intake among third-trimester pregnant women lowers placental and circulating concentrations of the antiangiogenic factor fms-like tyrosine kinase-1 (sFLT1). FASEB J. Epub November 29, 2012.

33. Jiang X, Yan J, West AA, et al. Maternal choline intake alters the epigenetic state of fetal cortisol-regulating genes in humans. FASEB J. 2012;26(8):3563-3574.

34. Shaw GM, Carmichael SL, Laurent C, Rasmussen SA. Maternal nutrient intakes and risk of orofacial clefts. Epidemiology. 2006;17(3):285-291.

35. Craciunescu CN, Albright CD, Mar MH, Song J, Zeisel SH. Choline availability during embryonic development alters progenitor cell mitosis in developing mouse hippocampus. J Nutr. 2003; 133(11):3614-3618

36. Glenn MJ, Gibson EM, Kirby ED, Mellott TJ, Blusztajn JK, Williams CL. Prenatal choline availability modulates hippocampal neurogenesis and neurogenic responses to enriching experiences in adult female rats. Eur J Neurosci. 2007;25(8):2473-2482.

37. Meck WH, Smith RA, Williams CL. Pre- and postnatal choline supplementation produces long-term facilitation of spatial memory. Dev Psychobiol. 1988;21(4):339-353.

38. Pyapali GK, Turner DA, Williams CL, Meck WH, Swartzwelder HS. Prenatal choline supplementation decreases the threshold for induction of long-term potentiation in young adult rats. $J$ Neurophysiol. 1998;79(7):1790-1796.

39. Glenn MJ, Kirby ED, Gibson EM, et al. Age-related declines in exploratory behavior and markers of hippocampal plasticity are attenuated by prenatal choline supplementation in rats. Brain Res. 2008;1237:110-123.

40. Poly C, Massaro JM, Seshadri S, et al. The relation of dietary choline to cognitive performance and white-matter hyperintensity in the Framingham Offspring Cohort. Am J Clin Nutr. 2011;94(6):1584-1591.

41. Cheatham CL, Goldman BD, Fischer LM, da Costa KA, Reznick JS, Zeisel SH. Phosphatidylcholine supplementation in pregnant women consuming moderate-choline diets does not enhance infant cognitive function: a randomized, double-blind, placebo-controlled trial. $\mathrm{Am} \mathrm{J}$ Clin Nutr. 2012;96(6):1465-1472.

42. Hoyme HE, May PA, Kalberg WO, et al. A practical clinical approach to diagnosis of fetal alcohol spectrum disorders: clarification of the 1996 institute of medicine criteria. Pediatrics. 2005;115(1):39-47.

43. Thomas JD, Idrus NM, Monk BR, Dominguez HD. Prenatal choline supplementation mitigates behavioral alterations associated with prenatal alcohol exposure in rats. Birth Defects Res A Clin Mol Teratol. 2010;88(10):827-837.

44. Thomas JD, Abou EJ, Dominguez HD. Prenatal choline supplementation mitigates the adverse effects of prenatal alcohol exposure on development in rats. Neurotoxicol Teratol. 2009;31(5):303-311.
45. Thomas JD, Biane JS, O’Bryan KA, O’Neill TM, Dominguez HD. Choline supplementation following third-trimester-equivalent alcohol exposure attenuates behavioral alterations in rats. Behav Neurosci. 2007;121(1):120-130.

46. Bremer J, Figard PH, Greenberg DM. The biosynthesis of choline and its relation to phospholipid metabolism. Biochim Biophys Acta. 1960;43:477-488

47. United States Department of Agriculture. USDA Database for the Choline Content of Common Foods, Release 2 (2008). Available from: http://www.ars.usda.gov/Services/docs.htm?docid=6232). Assessed March 10,2013.

48. Resseguie M, Song J, Niculescu MD, da Costa KA, Randall TA, Zeisel SH. Phosphatidylethanolamine N-methyltransferase (PEMT) gene expression is induced by estrogen in human and mouse primary hepatocytes. FASEB J. 2007;21(10):2622-2632.

49. Yan J, Wang W, Gregory JF 3rd, et al. MTHFR C677T genotype influences the isotopic enrichment of one-carbon metabolites in folate-compromised men consuming d9-choline. Am J Clin Nutr. 2011;93(2):348-355.

50. Chew TW, Jiang X, Yan J, et al. Folate intake, MTHFR genotype, and sex modulate choline metabolism in mice. $J$ Nutr. 2011;141(8): $1475-1481$.

51. Sweiry JH, Yudilevich DL. Characterization of choline transport at maternal and fetal interfaces of the perfused guinea-pig placenta. J Physiol. 1985;366:251-266.

52. Welsch F. Studies on accumulation and metabolic fate of (N-Me3H) choline in human term placenta fragments. Biochem Pharmacol. 1976;25(9):1021-1030.

53. Zeisel SH, Wurtman RJ. Developmental changes in rat blood choline concentration. Biochem J. 1981;198(3):565-570.

54. Zeisel SH, Epstein MF, Wurtman RJ. Elevated choline concentration in neonatal plasma. Life Sci. 1980;26(21):1827-1831.

55. Zeisel SH, Mar MH, Zhou Z, da Costa KA. Pregnancy and lactation are associated with diminished concentrations of choline and its metabolites in rat liver. J Nutr. 1995;125(12):3049-3054.

56. Fischer LM, da Costa KA, Galanko J, et al. Choline intake and genetic polymorphisms influence choline metabolite concentrations in human breast milk and plasma. Am J Clin Nutr. 2010;92(2):336-346.

57. Holmes-McNary MQ, Cheng WL, Mar MH, Fussell S, Zeisel SH. Choline and choline esters in human and rat milk and in infant formulas. Am J Clin Nutr. 1996;64(4):572-576.

58. Rohlfs EM, Garner SC, Mar MH, Zeisel SH. Glycerophosphocholine and phosphocholine are the major choline metabolites in rat milk. J Nutr. 1993;123(10):1762-1768.

59. Chao CK, Pomfret EA, Zeisel SH. Uptake of choline by rat mammarygland epithelial cells. Biochem J. 1988;254(1):33-38.

60. Yang EK, Blusztajn JK, Pomfret EA, Zeisel SH. Rat and human mammary tissue can synthesize choline moiety via the methylation of phosphatidylethanolamine. Biochem J. 1988;256(3): 821-828.

61. Zeisel SH, Char D, Sheard NF. Choline, phosphatidylcholine and sphingomyelin in human and bovine milk and infant formulas. $J$ Nutr. 1986;116(1):50-58.

62. Yan J, Jiang X, West AA, et al. Maternal choline intake modulates maternal and fetal biomarkers of choline metabolism in humans. Am J Clin Nutr. 2012;95(5):1060-1071.

63. da Costa KA, Sanders LM, Fischer LM, Zeisel SH. Docosahexaenoic acid in plasma phosphatidylcholine may be a potential marker for in vivo phosphatidylethanolamine $\mathrm{N}$-methyltransferase activity in humans. Am J Clin Nutr. 2011;93(5):968-974.

64. Cao D, Kevala K, Kim J, et al. Docosahexaenoic acid promotes hippocampal neuronal development and synaptic function. J Neurochem. 2009;111(2):510-521.

65. Sha W, da Costa KA, Fischer LM, et al. Metabolomic profiling can predict which humans will develop liver dysfunction when deprived of dietary choline. FASEB J. 2010;24(8):2962-2975. 
66. da Costa KA, Kozyreva OG, Song J, Galanko JA, Fischer LM, Zeisel SH. Common genetic polymorphisms affect the human requirement for the nutrient choline. FASEB J. 2006;20(9):1336-1344.

67. Kohlmeier M, da Costa KA, Fischer LM, Zeisel SH. Genetic variation of folate-mediated one-carbon transfer pathway predicts susceptibility to choline deficiency in humans. Proc Natl Acad Sci USA. 2005;102(44):16025-16030.

68. Resseguie ME, da Costa KA, Galanko JA, Patel M, Davis IJ, Zeisel SH. Aberrant estrogen regulation of PEMT results in choline deficiencyassociated liver dysfunction. J Biol Chem. 2011;286(2):1649-1658.

69. Ivanov A, Nash-Barboza S, Hinkis S, Caudill MA. Genetic variants in phosphatidylethanolamine $\mathrm{N}$-methyltransferase and methylenetetrahydrofolate dehydrogenase influence biomarkers of choline metabolism when folate intake is restricted. J Am Diet Assoc. 2009; 109(2):313-318.
70. Zeisel SH, Wishnok JS, Blusztajn JK. Formation of methylamines from ingested choline and lecithin. J Pharmacol Exp Ther. 1983; 225(2):320-324

71. Gelenberg AJ, Doller-Wojcik JC, Growdon JH. Choline and lecithin in the treatment of tardive dyskinesia: preliminary results from a pilot study. Am J Psychiatry. 1979;136(6):772-776.

72. Wang Z, Klipfell E, Bennett BJ, et al. Gut flora metabolism of phosphatidylcholine promotes cardiovascular disease. Nature. 2011; 472(7341):57-63.
International Journal of Women's Health

\section{Publish your work in this journal}

The International Journal of Women's Health is an international, peerreviewed open-access journal publishing original research, reports, editorials, reviews and commentaries on all aspects of women's healthcare including gynecology, obstetrics, and breast cancer. The manuscript management system is completely online and includes

\section{Dovepress}

a very quick and fair peer-review system, which is all easy to use. Visit http://www.dovepress.com/testimonials.php to read real quotes from published authors.

\footnotetext{
Submit your manuscript here: http://www.dovepress.com/international-journal-of-womens-health-journal
} 